\title{
Coronavirus's Impact on China's Economy
}

\author{
Yitong Xie \\ Rosedale Academy, Canada \\ 972100802@qq.com
}

\begin{abstract}
Since December 2019, the growth of global trade has slowed significantly during the years when the "COVID-19" was raging. Through a review of the literature, we explore the significant impact of the outbreak on the Chinese economy, mainly in the service and manufacturing sectors already e-commerce, with both negative and positive effects on these industries.
\end{abstract}

Keywords: COVID-19; Chinese economy; impact.

\section{Introduction}

Coronavirus pneumonia is called "2019 coronavirus" by the WHO. It refers to pneumonia caused by the 2019 New Coronavirus infection. Since December 2019, a number of cases of unexplained pneumonia associated with Southern China's seafood market have been found in some hospitals in Wuhan, Hubei. It has been confirmed as an acute respiratory infectious disease caused by 2019 New Coronavirus infection. On February 112020 WHO Director General Tan Desai announced in Geneva, Switzerland, the name of New Coronavirus pneumonia was "COVID-19". On February 22nd, the National Health and Health Commission issued a notice that the English name of New Coronavirus pneumonia was revised to "COVID-19". The novel coronavirus pneumonia epidemic was considered to be a global pandemic on March 11th. On April 4, China held national mourning activities. Over the past couple of years, the growth of global trade has slowed down significantly. "The CPB global cargo trade index shows that global trade volume decreased by $0.5 \%$ in 2019 compared with 2018, the first decline since the global financial crisis in 2008. It is expected that the new crown will further reduce global trade growth. Germany, Korea, Mexico and other countries with high trade dependence will face more severe challenges. The global intermediate products in the supply chain contribute to the total volume of goods trade. More than half of global supply chains are closely integrated. China, the United States and Germany have become the industrial chain hubs of East Asia, North America and Western Europe respectively."

\section{Literature review}

On January $28^{\text {th }}$, CNBC said that China's travel restrictions will impact other Asian economies during the New Coronavirus epidemic. The outbreak was predicted to have a huge impact on the Asia Pacific economy, especially in retail, catering, conferences, sports events, tourism and civil aviation. The reduction in China's outbound tourism was predicted to have a significant impact on the economies of Thailand, Japan, Vietnam and Australia. As China's inbound tourism itself accounts for a relatively small proportion of China's GDP, the reduction of inbound tourists has a very weak impact on China's economy."Amid the epidemic, the pessimism and panic have reflected on the stock market, which plunged more than $8 \%$ as the market reopened after the Spring Festival holiday. Businesses in the services sector, such as tourism, catering, entertainment, have suffered the most since they were required to shut down temporarily in order to control to spread of the virus. It seems that the Chinese government have been taking extremely strong measures to insure the containment of the virus. However, it is absolutely vital to control the situation as soon as possible to prevent further economic loss. "It might be better to have a short-term quarantine and have high short-term economic costs than to have a longer term where people are concerned about diseases floating around," said Anup Malani, an economist and professor at the University of Chicago. Also, experts expect that there would be a rebound for restaurants and tourism companies once the epidemic is over, as the epidemic will not completely eliminate the economic activities, but only 
postpone them to a later time. (The PBS) From the supply-side, Chinese factories and industries are known for their high efficiency and productivity, the temporary pause on production will be soon recovered once the epidemic is over. It is also worth mentioning that Chinese government has implemented multiple macro policies to minimize the negative effects and boost its economy including the injection of $\$ 173.8$ billion of liquidity into markets and a 10-basis-point cut to its regular reverse repos by the China's Central Bank. (The Observer) These market operations will drive down the interest rate and ease the financial pressure on enterprises."

\section{Analysis}

Over the past thousand years, China has experienced several kinds of epidemics and accidents. Three of the most prevalent epidemics include SARS in 2003, influenza a H1N1 in 2009 and H7N9 avian influenza in 2013 (Long \& Zhao, 2021). Among them, the SARS epidemic in 2003 has a relatively large impact and the short-term impact on the economy was also the largest. Due to the regional characteristics of the Wenchuan earthquake in 2008 and the global financial crisis in the United States in 2008, and the subsequent stimulus policies and international cooperation under the leadership of the G20, the Chinese government responded well to the impact of crises and accidents and maintained steady economic growth. However, the impact of the outbreak of coronavirus in early 2020 is very different from that before, which is highlighted in two aspects: on the one hand, the overall environment is different.

Internally, China's economy is in a transition period from high-speed growth to high-quality development, facing three key battles: preventing systemic financial risks, pollution prevention and poverty alleviation. The direct impact of the epidemic on China's economy is mainly in three areas: first, in the service industry, especially tourism, catering, culture and entertainment, as well as the logistics industry. Among them, the impact on small and medium-sized enterprises is more obvious.

The second key area is the manufacturing industry. Due to the uncertainty surrounding resumption time, the mobile phone, automobile, electronics and other industries will be greatly affected, which will also affect the global industrial chain. Wuhan, the core area of the epidemic, is also a region with manufacturing industries, and the impact is difficult to predict. The impact of the new coronavirus epidemic on the economy is different in various industries. . Among them, there are mainly negative impacts on tourism, transportation, retail, catering services, entertainment, exhibition, import and export and agriculture, while there are positive and negative impacts on the medical and health industry, pharmaceutical industry and network service industry at the same time. Indirectly related are agriculture, finance and insurance, securities industry, real estate industry, culture and education industry, etc. The losses suffered by tourism, transportation and other industries are intuitive, but they also have one side of the ebb and flow, and some industries even show a warming trend $(\mathrm{Wu}, 2021)$. In addition to rapidly increasing demand for medicine, medical devices, health protection, washing and disinfection products, which are closely related to the prevention and control of COVID-19, convenience food, audio-visual products, books and periodicals, fitness equipment, bicycles and even automobiles may be popular.

The COVID-19 epidemic has led to a decline in traditional commodity trading activities, but online transactions and e-commerce are becoming increasingly active. Some Chinese restaurants may have gone out of business, while some Chinese fast food and even "foreign fast food" are still booming because of the good dining environment and the way of dining. Different industries and enterprises have been affected differently in this period. In the field of trade, due to the panic caused by the epidemic and geopolitical factors, the measures taken by relevant countries to reduce or close aviation, ports and borders will have a negative impact on China's foreign trade and drag down China's economy. The resilience of China's economy should not be underestimated. The impact of the epidemic on the economy is not completely negative, and China's economy still has strong resilience. In the short term, the epidemic is not bad for all enterprises, such as e-commerce, online games and entertainment enterprises. At the same time, the financial support capacity of the 
Chinese government is obvious to all. In terms of epidemic control, as of January 29, 2020, China's governments at all levels had issued a total of 27.3 billion yuan of epidemic prevention and control subsidies to ensure the needs of epidemic prevention and control funds. The epidemic coincides with the key node in the formulation of the 14th five year plan. The economic support of the next five years' economic development plan is worth looking forward to. In the long run, as the world's second largest economy, China's huge potential in new economic fields such as consumption capacity, urbanization, 5G and artificial intelligence will not disappear due to the epidemic(Dhar, 2020).

\section{Robustness}

According to the macroeconomic data from the first quarter of 2020 released by the National Bureau of Statistics, the preliminary GDP figure was 20650.4 billion yuan, a year-on-year decrease of $6.8 \%$ (Vasiev et al, 2020). From the perspective of production, the added value of primary, secondary and tertiary industries decreased by $3.2 \%, 9.6 \%$ and $5.2 \%$ respectively. From the perspective of expenditure, the total investment in fixed assets (excluding farmers) in China was 8414.5 billion yuan, a year-on-year decrease of $16.1 \%$; The total per capita consumption expenditure of residents in China was 5082 yuan, a year-on-year nominal decrease of $8.2 \%$, and a real decrease of $12.5 \%$ after deducting price factors; the total trade surplus was 98.3 billion yuan, a year-on-year decrease of about $81 \%$; the total retail sales of social consumer goods in China was 7858 billion yuan, a year-on-year nominal decrease of $19.0 \%$, of which the catering revenue was 602.6 billion yuan, a year-on-year decrease of $44.3 \%$; the consumer price index rose by $4.9 \%$ over the same period last year, of which the year-on-year increase in March fell to 4.3\%; in February and March 2020, the national urban survey unemployment rate was $6.2 \%$ and 5.9\% respectively, an increase of $0.9 \%$ and $0.7 \%$ respectively over the same period last year.

In addition to industry and the service industry, the transportation industry, especially the transportation industry dominated by passenger transport, is facing a serious "operation crisis". For the three main modes of long-distance travel (railway, highway and civil aviation), the passenger volume decreased by more than $80 \%$ in February 2020, far lower than the level in the same period in the previous two years. In March, the railway passenger volume was 112.18 million, only $41 \%$ of that in January. This also reflects that, as of the end of March, all localities have strictly implemented prevention and control measures, people's travel has stagnated on a large scale, communication activities have decreased sharply, and a considerable number of migrant workers / students may not have returned to their previous posts (schools).

\section{Conclusions}

On the whole, the epidemic has a bad impact on China's economy. The epidemic hit the transportation, accommodation, catering, tourism and other service industries first, and became the biggest drag on economic growth. The growth rate of the tertiary industry in the first quarter of 2020 fell to a large extent compared with the end of last year. The delay of rework caused by the epidemic and the delay of migrant workers returning to the city will significantly drag down the growth of the secondary industry. However, after the epidemic eased, in the face of downward pressure on the economy, a series of steady growth measures, and the release of accumulated productivity in the early stage is also expected to provide an opportunity for the growth rate of the secondary industry to rebound after the epidemic eases. The longer the epidemic lasts, the greater the economic impact. At the same time, considering that the World Health Organization lists it as a public health emergency of international concern, the actual follow-up situation depends on the severity and duration of the epidemic. However, compared with other countries, China's economy has endured little impact due to the epidemic. The large-scale outbreak of the epidemic will have a huge impact on the Asia Pacific economy, especially retail, catering, conference, sports events, 
tourism, civil aviation and other industries. The reduction in China's outbound tourism will have a significant impact on the economies of Thailand, Japan, Vietnam and Australia. As China's inbound tourism itself accounts for a relatively small proportion of China's GDP, the reduction of inbound tourists has a very weak impact on China's economy.

\section{References}

[1] Long, H., \& Zhao, J.. (2021). The impact of sars epidemic and financial crisis on china's economy structure referenced to the potential impact of covid-19. Bulletin of Applied Economics, 8.

[2] Wu, F., Liu, G., Guo, N., Li, Z., \& Deng, X.. (2021). The impact of covid-19 on china's regional economies and industries. Journal of Geographical Sciences, 31 (4), 565-583.

[3] Dhar, B. K.. (2020). Impact of covid-19 on chinese economy. Economic Affairs, 9 (3/4), 23-26.

[4] Vasiev, M., Bi, K., Denisov, A., \& Bocharnikov, V.. (2020). How covid-19 pandemics influences chinese economic sustainability. Foresight and STI Governance (Foresight-Russia till No. 3/2015), 14. 